\title{
Research on the Mechanism of the Cultivation of Innovative High-skilled Talents in Electronic Commerce
}

\author{
Songjie GONG, Hemei MA \\ Zhejiang Business Technology Institute, Ningbo, 315012, China \\ email:songjie_gong@163.com
}

Keywords: Electronic Commerce; Cultivation; Innovative; High-skilled

\begin{abstract}
The talents who have innovative sense and high-skilled ability are required by not only the modern science and technology revolution, but also the economical and social development of a nation. In higher vocational teaching education, especially the teaching of electronic commerce with stronger practicality and operability, how to strengthen the cultivation of the students' ability of innovation and high-skilled is discussed from aspects, such as stimulating students' interest, the change of teaching mode, optimizing teaching methods, growth mechanism and so on. The paper researches on the mechanism of the cultivation of innovative high-skilled talents in electronic commerce. Given out that it is necessary in the higher vocational schools should take training innovative skilled talents and the approaches of training innovative skilled talents. All of these described a new way of the reformation of the higher vocational education.
\end{abstract}

\section{Introduction}

Innovation and education is to cultivate the people innovative spirit and ability as a basic value orientation of education. "21st Century Education Revitalization Action Plan clearly pointed to the overall advancement of quality education, and raising the overall quality and national innovation capacity. The striking creative ability, become the focus of attention of the education sector. Education was not only instill and management we usually understand its deeper meanings should be found to explore and strengthen the students 'creative potential and inspire students to creative thinking, develop students' creative spirit, creating a large number of creative talents. As a development patterns of Chinese higher education, vocational education is also an urgent need for innovation, and guide student learning and study of invention and innovation law of innovative ways to cultivate the students' innovative consciousness, innovative spirit and creative thinking, creativity, and physically labor-round development, making it a high-quality creative talent.

As the rapid development of the national economy, the huge demand for highly skilled personnel of innovative internal driving force to promote the innovative highly skilled personnel training system. But we must clearly see, currently in the not yet fully established the community to participate, training model is matured, powerful protection mechanisms the innovative highly skilled personnel training system. Accordingly, we must do the innovative highly skilled personnel training work systematic theoretical study must connotation of innovative high-skilled personnel, the nature of law and the impact of the characteristics and growth factors, and the only way to make innovative high-skilled personnel training work to achieve targeted. Therefore, in the current domestic and international innovative high-skilled personnel training and the macro context, a careful analysis of the situation and tasks of innovative high-skilled personnel training, from the perspective of the skills to develop a mechanism to study the growth of innovative highly skilled personnel generally law, to find effective ways and means of innovative high-skilled personnel training, so that not only conducive to good innovative culture of highly skilled personnel, but also conducive to building long-term development of innovative highly skilled workers. For this reason, the study of the law of growth of innovative high-skilled personnel and training system has important and far-reaching practical significance for the implementation of the "brain power" strategy put forward by the party and the country. 


\section{The mechanism of innovative high skill students' studio in E-commerce}

In the studio as infrastructure is to have advanced, open, service, level, production of "teaching, learning," one of the comprehensive school enterprise cooperation skills training "e-commerce specialty life studio". Make the students in the school training base can get skills competition, technology innovation test, teaching project training, enterprise project development, technical support and service and other real work exercise. It is to research and reform of the rationalization of the studio, the results, service, enterprise operation mechanism, as well as the cultivation of expertise, as shown in Figure 1.

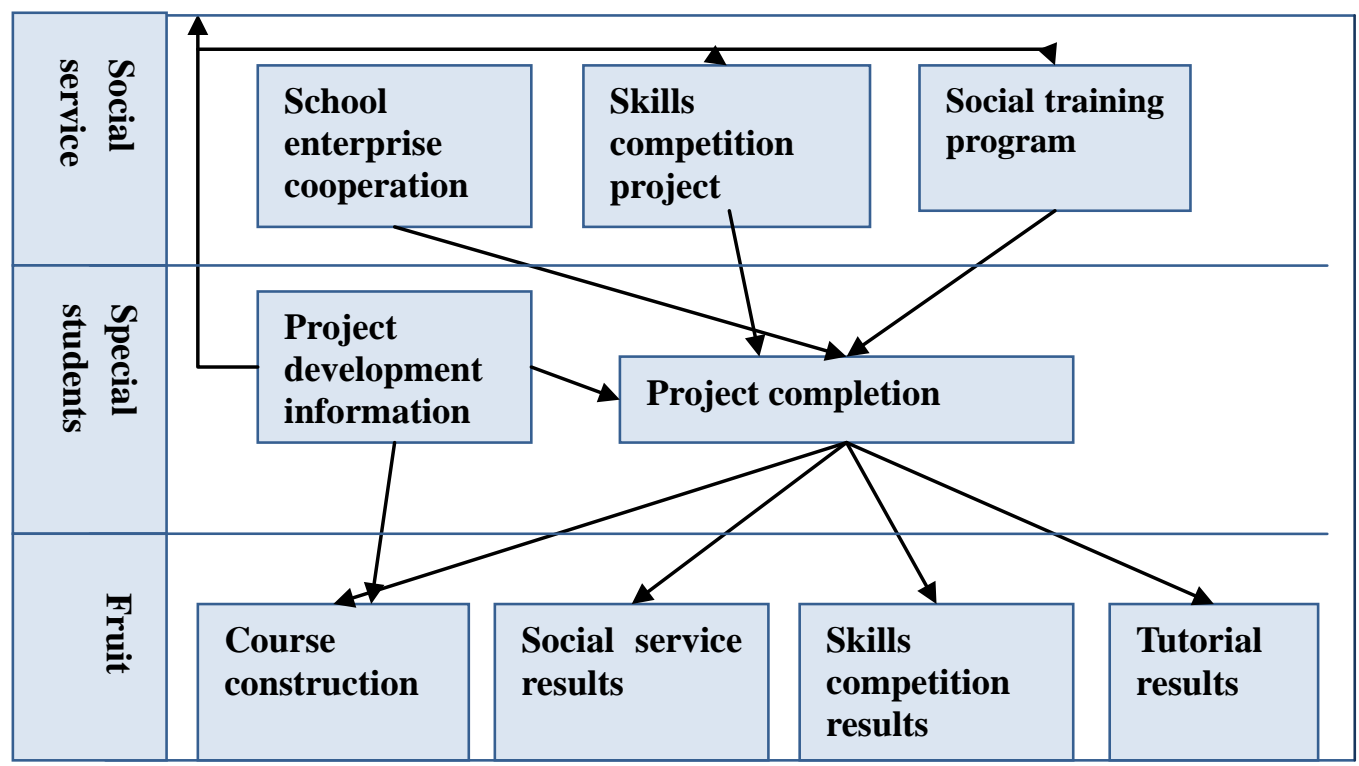

Figure 1 the mechanism of innovative high skill students' studio

\section{The curriculum system of innovative high - skill training for e-commerce}

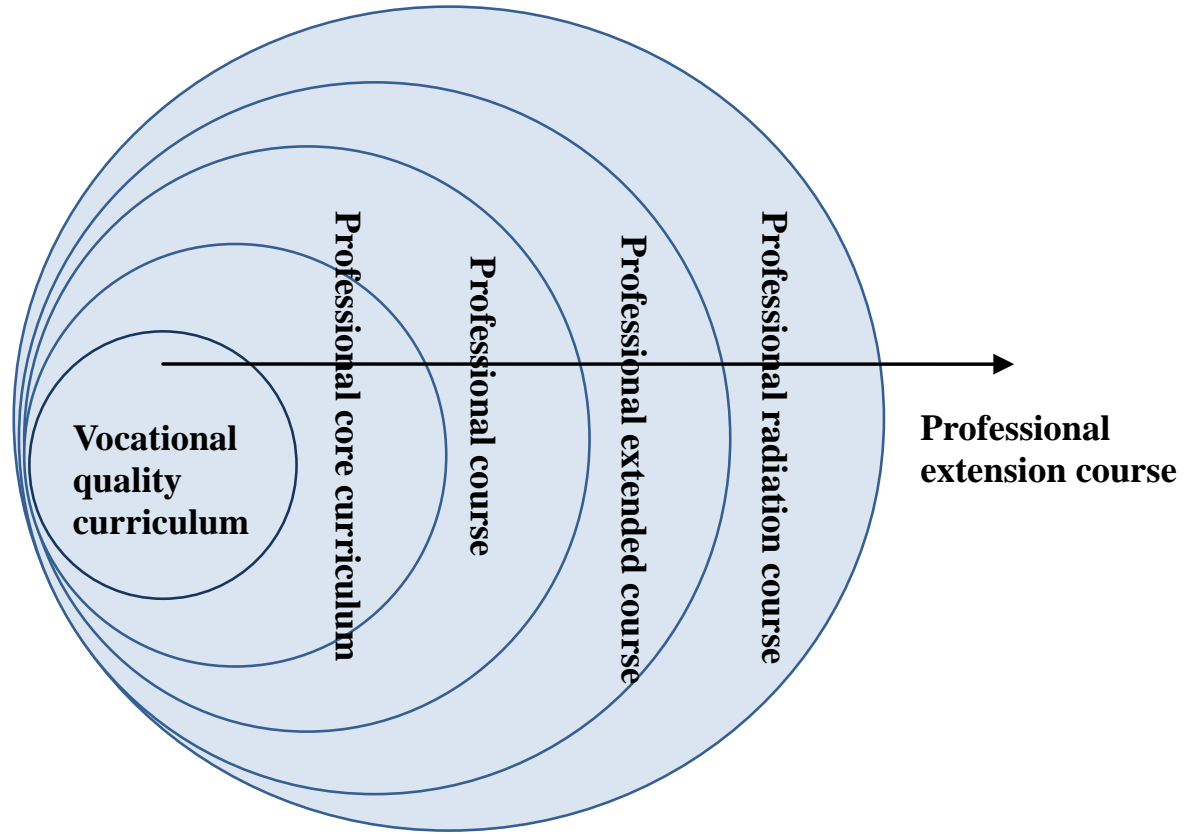

Figure 2 the curriculum system of innovative high - skill training

The establishment of e-commerce direction has the characteristics of sustained training of students, the organization of its competition, school enterprise project development and other 
activities. Strengthen the electronic commerce course, the webpage manufacture course, the multimedia curriculum project the reform, increases its multiplicity and the usability request. Establish project development results, skills competition results in alternative mechanisms and methods of comprehensive professional training achievement, strengthen school enterprise cooperation project development; carry out comprehensive experiments and the innovative experiment, students play creativity, such as shown in Figure 2.

\section{The implementation of the training of innovative high - skill talents for e-commerce}

In the teaching reform, the emphasis is on the reform of the curriculum and the innovation of the teaching mode. The curriculum reform insists on the combination of curriculum and vocational requirements, and the content of curriculum and vocational qualification is the combination of the content of curriculum reform and vocational qualification.. According to the requirement of "double certificate of one education", the vocational qualification standards as the important teaching objective, and vigorously promote the development of the integrated curriculum, Double Certificate Curriculum and integrated curriculum. In the last two years, with the deepening of the reform, the course of the course is the subject of the reform of the college education, and a number of projects of the task of the job are developed. According to the theoretical teaching and practical teaching a high degree of integration of thinking in teaching reform, the implementation of the ability training as the main line, the set of theoretical teaching and experimental training practice in various teaching mode, a representative product of teaching, teaching units, teaching studios, post practice teaching, project teaching, as shown in Figure 3.

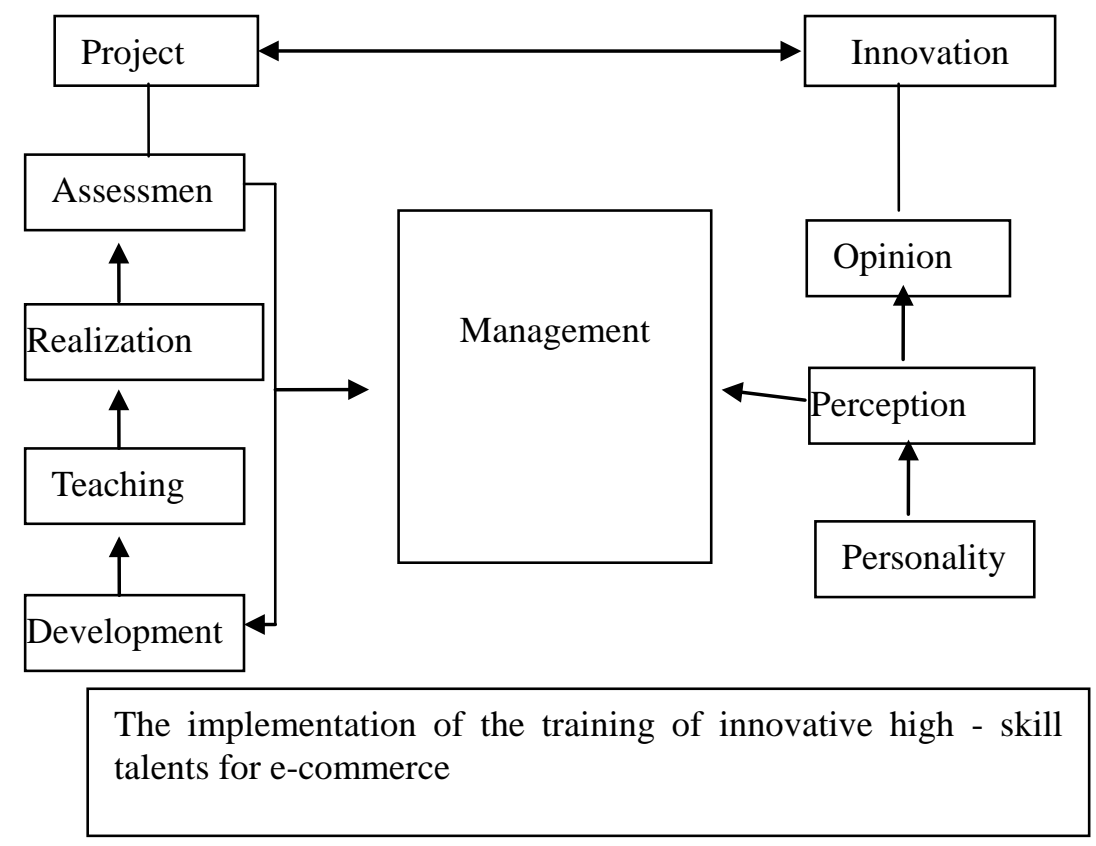

Figure 3 the implementation of the training of innovative high-skilled talents

\section{The curriculum system of innovative high - skill training for e-commerce}

(1) The establishment of the talent training mechanism is the goal of the electronic commerce innovation high skilled personnel. There are the formation of enterprise cooperation management mechanism, the project management mechanism, teaching project construction mechanism, the teaching mechanism of study and study of engineering and engineering. Improve the effect of the cultivation of the innovative high skills of e-commerce, and improve the experience of students' experience.

(2) The development of the project as the carrier, innovative e-commerce and high skilled personnel training mechanism, and explore new methods for the cultivation of e-commerce. It is to 
establishment of campus e-commerce innovation training room, the implementation of the prospective enterprise management, to e-commerce project development and technology support training students of technological innovation and the electronic commerce project management ability as the main content, to establish a set of effective electronic business affairs specialty cultivation mechanism and methods. Improve the students' electronic commerce, web production, multimedia production of theoretical knowledge level and practical ability.

(3) Building a course system of e-commerce based on the position of the job. According to the "integration of professional standards, the implementation of project teaching, pay attention to the effect evaluation of the curriculum construction of the guiding ideology, the construction of the curriculum system of e-commerce integration, each a post course were to project development and technology innovation as the core, school enterprise joint development.

\section{Conclusion}

The talents who have innovative sense and high-skilled ability are required by not only the modern science and technology revolution, but also the economic and social development of a nation. In this paper, we research on the mechanism of the cultivation of innovative high-skilled talents in electronic commerce. Given out that it is necessary in the higher vocational schools should take training innovative skilled talents and the approaches of training innovative skilled talents. All of these described a new way of the reformation of the higher vocational education.

\section{Acknowledgement}

A Project Supported by Fund of Zhejiang Province Education Science Planning Office (Key Program, "Research on the Mechanism of the Cultivation of Innovative High-skilled Talents in Electronic Commerce", Grant No. 2015SB103).

Supported by University Students' Scientific and Technological Innovation Project of Zhejiang Business Technology Institute.

\section{References}

[1] Songjie Gong, A Collaborative Filtering Recommendation Algorithm Based on Trust Network and Trust Factor, Journal of Convergence Information Technology, Vol. 8, No. 5, pp. 1111 1118, 2013.03.

[2] Songjie Gong, Research on the Growth Mechanism of High-Skilled System in Computer Science and Technology, Applied Mechanics and Materials, Vol. 513, pp: 2748-2751, 2014.

[3] Guang-yu C. Innovation and practice of training high-skilled workers by school-enterprise cooperation in higher vocational education[C]//Knowledge Acquisition and Modeling (KAM), 2011 Fourth International Symposium on. IEEE, 2011: 549-551.

[4] Jin-song W E N Y Z, Zhi-qing P Y X. The Study on Training Innovative Skilled Talents. Journal of Hunan Industry Polytechnic, 2006, 1: 042.

[5] Jide Z. Study on the Adaptability of High-skilled Talents Cultivation and Market Demand in Guangzhou . Vocational and Technical Education, 2007, 28: 009.

[6] Songjie Gong, Liping Zeng, The Solution of Safety of Electronic Cash in E-Commerce under Cloud Computing Environment, Advanced Materials Research, Vol. 989, pp: 4314-4317, 2014.

[7] Songjie Gong, Research on Attack on Collaborative Filtering Recommendation Systems, AISS: Advances in Information Sciences and Service Sciences, Vol. 5, No. 10, pp. 938 946, 2013.05 